\title{
BMJ
}

\section{Patterns of alcohol consumption and ischaemic heart disease in culturally divergent countries: the Prospective Epidemiological Study of Myocardial Infarction (PRIME)}

\author{
Jean-Bernard Ruidavets, medical doctor, researcher in epidemiology, ${ }^{1}$ Pierre Ducimetière, senior \\ epidemiology researcher, study coordinator, ${ }^{2}$ Alun Evans, emeritus professor of epidemiology, ${ }^{3}$ Michèle \\ Montaye, medical doctor, ${ }^{4}$ Bernadette Haas, medical doctor, researcher in epidemiology, ${ }^{5}$ Annie Bingham, \\ research epidemiologist, study coordinator, ${ }^{6}$ John Yarnell, reader in cardiovascular epidemiology, ${ }^{3}$ Philippe \\ Amouyel, professor of public health, ${ }^{4}$ Dominique Arveiler, medical doctor, researcher in epidemiology, ${ }^{5}$ Frank \\ Kee, professor of public health medicine, ${ }^{3}$ Vanina Bongard, associate professor of medicine, ${ }^{1}$ Jean Ferrières, \\ professor of medicine ${ }^{7}$
}

'Department of Epidemiology, INSE RM U558, Toulouse University School of Medicine, Toulouse, France

${ }^{2}$ INSERM-Paris XI University, Villejuif, France

${ }^{3}$ UK Clinical Research

Collaboration Centre of Excellence for Public Health, Queen's

University Belfast, Belfast, UK

${ }^{4}$ Department of Epidemiology and Public Health, INSERM U744, Pasteur Institute of Lille, Lille,

France

${ }^{5}$ Department of Epidemiology and Public Health, EA 3430, Medical Faculty, University of Strasbourg, Strasbourg, France

${ }^{6}$ INSERM U970, Paul Brousse Hospital, Villejuif, France

${ }^{7}$ Department of Cardiology B and Department of Epidemiology, INSERM U558, Toulouse

University Hospital, Toulouse, France

Correspondence to: J-B Ruidavets jean-bernard.ruidavets@cict.fr

Cite this as: $B M J$ 2010;341:c6077 doi:10.1136/bmj.c6077

\section{ABSTRACT}

Objective To investigate the effect of alcohol intake patterns on ischaemic heart disease in two countries with contrasting lifestyles, Northern Ireland and France. Design Cohort data from the Prospective Epidemiological Study of Myocardial Infarction (PRIME) were analysed. Weekly alcohol consumption, incidence of binge drinking (alcohol $>50 \mathrm{~g}$ on at least one day a week), incidence of regular drinking (at least one day a week, and alcohol $<50 \mathrm{~g}$ if on only one occasion), volume of alcohol intake, frequency of consumption, and types of beverage consumed were assessed once at inclusion. All coronary events that occurred during the 10 year follow-up were prospectively registered. The relation between baseline characteristics and incidence of hard coronary events and angina events was assessed by Cox's proportional hazards regression analysis.

Setting One centre in Northern Ireland (Belfast) and three centres in France (Lille, Strasbourg, and Toulouse).

Participants 9778 men aged 50-59 free of ischaemic heart disease at baseline, who were recruited between 1991 and 1994.

Main outcome measures Incident myocardial infarction and coronary death ("hard" coronary events), and incident angina pectoris.

Results A total of 2405 men from Belfast and 7373 men from the French centres were included in the analyses, 1456 (60.5\%) and 6679 (90.6\%) of whom reported drinking alcohol at least once a week, respectively. Among drinkers, $12 \%(173 / 1456)$ of men in Belfast drank alcohol every day compared with $75 \%(5008 / 6679)$ of men in France. Mean alcohol consumption was $22.1 \mathrm{~g} /$ day in Belfast and $32.8 \mathrm{~g} /$ day in France. Binge drinkers comprised $9.4 \%(227 / 2405)$ and $0.5 \%(33 / 7373)$ of the Belfast and France samples, respectively. A total of 683 (7.0\%) of the 9778 participants experienced ischaemic heart disease events during the 10 year follow-up: 322 (3.3\%) hard coronary events and 361 (3.7\%) angina events. Annual incidence of hard coronary events per 1000 person years was 5.63 (95\% confidence interval 4.69 to 6.69$)$ in Belfast and 2.78 (95\% Cl 2.41 to 3.20) in France. After multivariate adjustment for classic cardiovascular risk factors and centre, the hazard ratio for hard coronary events compared with regular drinkers was 1.97 (95\% Cl 1.21 to 3.22) for binge drinkers, 2.03 (95\% $\mathrm{Cl} 1.41$ to 2.94$)$ for never drinkers, and $1.57(95 \% \mathrm{Cl} 1.11$ to 2.21) for former drinkers for the entire cohort. The hazard ratio for hard coronary events in Belfast compared with in France was $1.76(95 \% \mathrm{Cl} 1.37$ to 2.67$)$ before adjustment, and 1.09 (95\% Cl 0.79 to 1.50$)$ after adjustment for alcohol patterns and wine drinking. Only wine drinking was associated with a lower risk of hard coronary events, irrespective of the country.

Conclusions Regular and moderate alcohol intake throughout the week, the typical pattern in middle aged men in France, is associated with a low risk of ischaemic heart disease, whereas the binge drinking pattern more prevalent in Belfast confers a higher risk.

\section{INTRODUCTION}

The World Health Organization estimates that 17.1 million people died from cardiovascular diseases in 2004 , which represents $29 \%$ of all deaths. ${ }^{1}$ Of these deaths, 7.2 million resulted from coronary heart disease and 5.7 million from stroke. In 2004, cardiovascular disease accounted for nearly $10 \%$ of the burden of disease attributable to alcohol in men worldwide. $^{2}$

In Europe in 2006, 28\% of the population more than 15 years of age reported that they consumed five or more alcoholic drinks (50 g alcohol) on one occasion at least once a week, ${ }^{3}$ but the prevalence of binge drinking varied considerably across countries. Recent data from the Centers for Disease Control and Prevention indicate that excessive alcohol drinking is responsible for approximately 79000 deaths a year in the United States. ${ }^{4}$ 
Conversely, many observational studies have reported inverse associations between some behaviours related to alcohol consumption and ischaemic heart disease. ${ }^{5-10}$

The role of specific alcoholic beverages - that is, wine, beer, or spirits - in ischaemic heart disease is still debated. ${ }^{11-14}$ The relation between ischaemic heart disease and the type of beverage consumed is often considered a proxy for more complex inter-relations between lifestyle, diet, and socioeconomic factors. ${ }^{15-17}$ Drinking patterns, however, cannot be summarised simply in terms of total intake and beverage preference.

The role of the regularity of alcohol consumption throughout the week and the effect of heavy regular or binge drinking on cardiovascular mortality and morbidity are factors that have recently aroused inter est. ${ }^{18-23}$ Moreover, few studies have looked at outcomes in countries where lifestyle and drinking habits are known to contrast markedly. Variation in such behaviours could lead to different incidence of ischaemic heart disease. For example, the incidence of ischaemic heart disease is higher in Northern Ireland than in France. ${ }^{24}$ Is it possible that this disparity could be the result, at least partly, of the alcohol behaviours specific to each country? To assess these issues, we used data from the Prospective Epidemiological Study of Myocardial Infarction (PRIME) cohort to analyse the patterns of alcohol consumption and their relation to the incidence of "hard" coronary events (myocardial infarction and coronary death) and angina pectoris events in men aged 50-59 years in Belfast, Northern Ireland, and in three cities in France.

\section{METHODS}

Population sampling

According to data from the WHO Multinational Monitoring of Trends and Determinants in Cardiovascular Disease (MONICA) project, ${ }^{24}$ the ratio of incident myocardial infarction and coronary death in Northern Ireland (Belfast) compared with in France (Toulouse, Strasbourg, and Lille) was between 2:1 and 3:1.We used results of the MONICA project to calculate the sample size for a country specific analysis of ischaemic heart disease in PRIME, which used the same populations. Observation of 100 cases within each country cohort would permit detection of a hazard ratio of about 1.8 (with risks $\alpha=0.05$ and $\beta=0.20$ ), associated with an exposure factor prevalence of 0.5 . To allow identification of this number of events, a sample size of 2500 men in Northern Ireland and 7500 in France observed over a five year period was designated a priori. Lower than expected numbers of cases were observed in PRIME, however, owing to the important reduction in the rates of coronary heart disease during the 90 s, especially in Northern Ireland. It was thus decided to extend follow-up to 10 years for many risk factors analysed in PRIME.

In the Northern Ireland PRIME centre-Belfastthe sampling frame was based on industry, the civil service, and general practice. In the three French centres-Lille, Strasbourg, and Toulouse - the sampling frame was health screening centres for free medical examinations (organised by the social security system and offered to each person) and occupational medicine settings where each worker was examined annually. Each sample was recruited to match broadly the social class structure of the background population. Every man selected was invited to participate in the study, and participation was voluntary. Individuals were informed of the aim of the study and signed a consent form that included agreement to annual follow-up. Approval from the appropriate local ethics committee was obtained in each study centre. ${ }^{25}$

\section{Baseline measurements}

\section{Questionnaires}

Participants completed self administered questionnaires relating to demographic and socioeconomic factors at home. The men then attended a clinic, where questionnaires were carefully checked by the interviewer to identify missing responses and each question (and the corresponding response) was discussed with the participant. The consistency and relevance of each response was assessed by the interviewer.

Data were collected on years of full time education, occupation, personal and family history, tobacco and alcohol consumption, drug intake, and physical activity. Cumulative tobacco consumption was quantified as pack years. Pack years were calculated by multiplying the number of packs (defined as 20 manufactured cigarettes) of cigarettes smoked a day by the number of years the person had smoked. A questionnaire on personal medical history and the London School of Hygiene \& Tropical Medicine Cardiovascular (Rose) Questionnaire for Chest Pain on Effort and Possible Infarction ${ }^{26}$ were also completed. The Rose questionnaire is a standardised and validated questionnaire that evaluates the usual characteristics of chest pain and discomfort. When a participant responded negatively to the first two questions (chest pain and discomfort), the rest were skipped. If the individual answered positively, the occurrence of chest pain at rest or on exertion, the intensity, location, and duration of the chest pain or discomfort were then documented.

\section{Clinical measurements}

Height and weight were measured using a standard protocol, and body mass index was calculated as weight $/$ height ${ }^{2}\left(\mathrm{~kg} / \mathrm{m}^{2}\right)$. Blood pressure was measured at the end of the examination after a five minute rest in the sitting position. Measurements were performed with an automatic device (Spengler SP9; Spengler, Asnières sur Seine, France), which also recorded heart rate. A standard cuff size was used, but a larger cuff was available when necessary. A standard 12 lead electrocardiogram was recorded.

\section{Biological measurements}

A fasting blood sample was drawn from each participant, and the plasma was prepared with EDTA and used for analysis of lipids. Plasma total cholesterol and triglycerides were measured by enzymatic methods using reagents from Boehringer Ingelheim 
(Mannheim, Germany). Apolipoproteins A-1 and B were measured by a nephelometric method (Behringwerke; Marburg, Germany).

\section{Assessment of alcohol intake}

Weekly alcohol consumption was evaluated by assessing the different types of beverage consumed (for example, wine or beer) and their alcohol content (such as $10 \%$ wine, $12 \%$ wine, $4 \%$ beer, or $5 \%$ beer). Participants' present alcohol intake, defined by the level of consumption during the week before examination, was evaluated by interview using a questionnaire that was administered, as far as possible, along with the food frequency questionnaire. If, for some reason, the alcohol consumption for that week appeared to differ from the usual consumption of the participant, the interviewer had to refer to an earlier week that corresponded to a more usual or normal intake. The interview covered consumption during each normal day of the week, including at meals and between meals, for the following times: before breakfast; breakfast; morning; lunch; afternoon; dinner; evening; and night. Age at which regular alcohol consumption began was recorded.

Participants were classified according to their usual alcohol drinking habits. Four groups were defined: never drinkers; former drinkers; regular drinkers; and binge drinkers. The alcohol measurement unit used was the drink. Half drinks or quarter drinks were also used to estimate quantities. One drink of alcohol was standardised as 10-12 $\mathrm{g}$ of ethanol.

Men who had never consumed alcohol before inclusion in the study were labelled "never drinkers." "Former drinkers" corresponded to men who had quit alcohol consumption for different reasons and declared no consumption at inclusion in the study. Among non-drinkers at inclusion (never drinkers + former drinkers; $\mathrm{n}=949$ and $\mathrm{n}=694$ in Belfast and France, respectively), $46.1 \%(\mathrm{n}=438)$ had quit drinking in Belfast and 69.7\% $(\mathrm{n}=484)$ in France.

Regular consumption was arbitrarily defined as the intake of at least three "usual amounts" a week for a period of at least three consecutive months, irrespective of the type of beverage. "Regular drinkers" comprised men who drank alcohol on at least one day a week, and, if drinking on only one occasion, consumed less than $50 \mathrm{~g}$ of alcohol. Daily alcohol intake was categorised into four groups at intervals of $25 \mathrm{~g}$ : 1-24 g; 25-49 g; 50-74 g; and $75 \mathrm{~g}$ or more. Intake was also ranked according to the weekly frequency of alcohol consumption: 1 day; 2-3 days; 4-5 days; and 6-7 days. The average total daily alcohol intake was calculated firstly on the basis of a typical week's consumption, irrespective of whether consumption was daily or not, and secondly on the basis of the number of days on which alcohol was consumed.

Binge drinking was defined as excessive alcohol intake over a short period on one occasion each week. No standard definition of excessive intake for use in epidemiological studies exists. In the literature, the threshold used depends on, for example, the population, the country studied, and the time spent drinking alcohol. In the present study, the threshold for "binge drinkers" was set at $50 \mathrm{~g}$ of alcohol on at least one day a week, because this level is the minimal quantity most often used to define binge drinking in similar population studies. Binge drinking is not an occasional weekly behaviour because it occurs regularly each week, and this agrees with the methodology adopted in PRIME (alcohol consumption assessed on a typical week over the year before examination).

\section{Pre-existing ischaemic heart disease}

Participants were considered to have a history of ischaemic heart disease at entry if one of the following was observed: (a) myocardial infarction, angina pectoris, or both, diagnosed by a physician; $(b)$ electrocardiographic evidence of myocardial infarction, defined as major or moderate $Q$ waves coded using the Minnesota system; or $(c)$ a positive Rose chest pain questionnaire. $^{27}$

\section{Follow-up}

After baseline examination, participants were contacted annually by letter or by telephone on the anniversary of inclusion and asked to complete a clinical event questionnaire. The questionnaire collected information about possible hospitalisation, medical consultation, and new treatment or modification to existing treatment, whatever the medical problem. Specific questions about angina pectoris, myocardial infarction, stroke, and peripheral arterial disease were also included.

For all participants reporting a possible clinical event, clinical information was sought directly from the relevant hospital or family doctors' notes. All details of electrocardiograms, hospital admissions, biomarkers for myocardial infarction, surgical operations, coronary angioplasty, myocardial perfusion scintigraphy, echocardiography, and medical treatment were collected. Death certificates were checked for supporting clinical and postmortem information on cause of death. A medical committee comprising one member of each PRIME centre, the coordinating centre, and three independent cardiologists was established to examine medical data relating to all suspected events. The committee assigned a code to each event according to a standardised protocol: myocardial infarction; coronary death; or angina pectoris. ${ }^{28}$ Myocardial infarction and coronary death were classified as "hard" coronary events.

\section{Statistical analysis}

Mean annual incidence of ischaemic heart disease in men free of coronary disease at study entry was calculated using the number of person years of follow-up in each country. Incident hard coronary events were counted only once, whether preceded by a diagnosis of angina pectoris or not. Conversely, incident angina pectoris events (stable or unstable) were counted once, but were not counted when they developed after a hard coronary event.

The relation between baseline variables and the incidence of hard coronary events (or angina pectoris) was 
assessed using Cox's proportional hazards regression analysis. Adjustment was made for the following factors known to be predictive of ischaemic heart disease: circumference; cumulative tobacco consumption (pack years); systolic blood pressure; apolipoprotein A-1 concentration; apolipoprotein B concentration; and treatment for diabetes, dyslipidaemia, and hypertension. The validity of the proportional hazards ratios assumption for the covariates was verified. We tested the proportionality assumption using cumulative sums of martingale based residuals. ${ }^{29}$ Analyses were conducted first for each country separately and then for the whole cohort, after testing the homogeneity of relations between the two samples. All statistical analyses were carried out using the SAS statistical software package (SAS Institute, Cary, NC). All tests were considered significant at $\mathrm{P}=0.05$.

\section{RESULTS}

Between May 1991 and January 1994, a sample of 10600 men aged 50-59 years was examined in one centre in Northern Ireland (Belfast; $n=2745$ ) and three centres in France-Lille in the north $(n=2633)$, Strasbourg in the east $(n=2612)$, and Toulouse in the south west $(n=2610)$. Of these 10600 participants, 842 (7.9\%) were excluded because of a medically diagnosed history of angina pectoris or myocardial infarction, or because of chest pain at entry according to the Rose questionnaire. A total of 317 $(3.0 \%)$ men were lost to follow-up after 10 years, $215(2 \%)$ refused to continue participating in the study, and 653 $(6.1 \%)$ died in the course of follow-up. The proportion of refusals and participants lost to follow-up was similar in Belfast and the French centres (150/2745 (5.5\%) and $382 / 10600(3.6 \%)$, respectively). The number of men included was 9778 in total: 2405 and 7373 in Belfast and in the French centres, respectively.

\section{Patterns of alcohol consumption}

A total of 1456 (60.5\%) of the 2405 men in Belfast and $6679(90.6 \%)$ of the 7373 men at the French centres reported drinking alcohol at least once a week. Only half of the drinkers in Belfast were regular drinkers compared with most alcohol drinkers in France (1229/2405 (51.1\%) and 6646/7373 (90.1\%), respectively), whereas $227(9.4 \%)$ men in Belfast and 33 $(0.5 \%)$ in France were binge drinkers (table 1). Among drinkers, 5008 (75\%) in France drank alcohol every day, whereas in Belfast only 173 (11.9\%) drank daily and $1052(72.2 \%)$ drank on one, two, or three days a week. The proportion of men in Belfast who drank alcohol was two to threefold higher on Fridays age; years of education; level of physical activity; waist

(937/2405 (39\%)) and Saturdays (1231/2405 (51\%) compared with the other days of the week.

Drinkers in Belfast mainly consumed beer (1100/1456 $(75.5 \%))$, followed by spirits $(892 / 1456(61.3 \%))$, with a small minority consuming wine (399/1456 (27.4\%)). In stark contrast, wine was predominantly consumed in the French centres $(6134 / 6679(91.8 \%))$, followed by liquor $(4941 / 6679(74.0 \%))$ and, less frequently, beer (3770/6679 (56.4\%)).

In France, the proportions of non-drinkers were comparable across centres: $8.2 \%(\mathrm{n}=199)$ in Strasbourg, 9.7\%, $(\mathrm{n}=243)$ in Toulouse, and 10.3\% $(\mathrm{n}=252)$ in Lille. Among drinkers, the numbers of men who drank every day were similar in Strasbourg, Toulouse, and Lille ( $\mathrm{n}=1689$ (75.3\%), $\mathrm{n}=1631 \quad(72.2 \%)$, and $\mathrm{n}=1688(77.3 \%)$, respectively). The most significant difference between the centres was in the type of alcohol consumed: in Toulouse $83 \%$ of alcohol consumed was as wine, whereas in Strasbourg and Lille only 63\% and $61 \%$, respectively, was consumed as wine, most of the rest of the alcohol being provided by beer.

\section{Amount of alcohol consumed}

Among regular drinkers, the total volume of alcohol consumed over a week was practically identical in Belfast and in France (281.7 g (SD 279.2) v 254.6 g (198.1); table 1). Mean daily alcohol consumption was $22.1 \mathrm{~g}$ in Belfast and $32.8 \mathrm{~g}$ in France. However, the alcohol volume tended to be consumed on one or two days in participants from Belfast and throughout the week in people enrolled at the three French centres. Mean alcohol consumption was 2-3 fold higher at weekends in Belfast than in France. On Fridays, drinkers in Belfast consumed on average $61.1 \mathrm{~g}$ (74.3) of alcohol compared with $33.7 \mathrm{~g}$ (29.8) in France, and on Saturdays the respective means were $91.4 \mathrm{~g}(84.3)$ and $41.1 \mathrm{~g}$ (31.8). Among drinkers in France, the quantities of alcohol consumed daily were similar in Strasbourg, Toulouse, and Lille (36.6 g/day, $33.0 \mathrm{~g} /$ day, and $39.2 \mathrm{~g} /$ day, respectively).

Baseline characteristics stratified by level of alcohol consumption are shown in table 2 . Irrespective of centre, higher alcohol consumption was associated with increased levels of smoking; higher total cholesterol, high density lipoprotein cholesterol, apolipoprotein A-1, and triglyceride levels; and raised blood pressure $(\mathrm{P}=0.001$ for all). In France, non-drinkers were more likely to be receiving treatment for diabetes $(\mathrm{P}=0.003)$, and higher alcohol consumption was associated with higher body mass index, waist circumference, and apolipoprotein B levels. Low educational

\begin{tabular}{|c|c|c|c|c|c|c|c|}
\hline & \multirow{2}{*}{$\begin{array}{c}\text { Non-drinkers } \\
\text { n (\%) }\end{array}$} & \multicolumn{3}{|c|}{ Binge drinkers } & \multicolumn{3}{|c|}{ Regular drinkers } \\
\hline & & n (\%) & $\begin{array}{l}\text { Daily (mean } \\
\text { (SD) (g)) }\end{array}$ & $\begin{array}{l}\text { Weekly (mean } \\
\text { (SD) (g)) }\end{array}$ & n (\%) & $\begin{array}{l}\text { Daily (mean } \\
\text { (SD) (g)) }\end{array}$ & $\begin{array}{l}\text { Weekly (mean } \\
\text { (SD) (g)) }\end{array}$ \\
\hline Belfast & 949 (39.5) & $227(9.4)$ & $17.5(8.3)$ & $122.7(57.9)$ & $1229(51.1)$ & $40.2(39.9)$ & $281.7(279.2)$ \\
\hline France & $694(9.4)$ & $33(0.5)$ & $10.0(3.7)$ & $69.8(25.9)$ & 6646 (90.1) & $36.4(28.3)$ & $254.6(198.1)$ \\
\hline
\end{tabular}


Table 2|Baseline characteristics according to level of alcohol consumption in Belfast and the French centres

\begin{tabular}{|c|c|c|c|c|c|c|c|c|c|c|c|c|}
\hline & \multicolumn{6}{|c|}{ Belfast } & \multicolumn{6}{|c|}{ French centres } \\
\hline & $\begin{array}{c}\text { Non- } \\
\text { drinkers }\end{array}$ & $\begin{array}{c}1-24 \mathrm{~g} / \\
\text { day }\end{array}$ & $\begin{array}{l}25-49 \mathrm{~g} / \\
\text { day }\end{array}$ & $\begin{array}{l}50-74 \mathrm{~g} / \\
\text { day }\end{array}$ & $\begin{array}{l}\geq 75 \mathrm{~g} / \\
\text { day }\end{array}$ & $P$ value & $\begin{array}{l}\text { Non- } \\
\text { drinkers }\end{array}$ & $\begin{array}{l}1-24 \mathrm{~g} / \\
\text { day }\end{array}$ & $\begin{array}{l}25-49 \mathrm{~g} / \\
\text { day }\end{array}$ & $\begin{array}{l}50-74 \mathrm{~g} / \\
\text { day }\end{array}$ & $\begin{array}{l}\geq 75 \mathrm{~g} / \\
\text { day }\end{array}$ & $P$ value \\
\hline n (\%) & 949 (39.5) & $576(23.9)$ & $418(17.4)$ & $222(9.2)$ & $240(10.0)$ & - & $694(9.4)$ & $\begin{array}{l}2217 \\
(30.1)\end{array}$ & $\begin{array}{l}1996 \\
(27.1)\end{array}$ & $\begin{array}{l}1332 \\
(18.0)\end{array}$ & $\begin{array}{l}1134 \\
(15.4)\end{array}$ & - \\
\hline Age (years) & $54.8(2.9)$ & $54.8(2.9)$ & $54.6(3.0)$ & $54.6(2.9)$ & $54.5(2.8)$ & 0.23 & $54.9(2.8)$ & 54.9 (2.9) & 54.9 (2.9) & $55.0(2.9)$ & $54.9(2.8)$ & 0.78 \\
\hline Years of education & $11.3(3.0)$ & $11.7(2.9)$ & $11.3(2.5)$ & $10.8(2.3)$ & $10.3(2.0)$ & 0.001 & $10.0(4.8)$ & $11.9(3.7)$ & $11.7(3.5)$ & $11.5(3.3)$ & $10.9(3.3)$ & 0.001 \\
\hline $\begin{array}{l}\text { Level of physical activity } \\
\text { (proportion sedentary (\%)) }\end{array}$ & 5.6 & 4.2 & 7.9 & 11.3 & 11.3 & 0.001 & 25.6 & 14.8 & 13.2 & 12.3 & 15.8 & 0.001 \\
\hline \multicolumn{13}{|l|}{ Smoking habits } \\
\hline Never smoker (\%) & 48.2 & 35.2 & 22.7 & 18.0 & 20.4 & 0.001 & 34.6 & 35.3 & 29.0 & 20.6 & 14.9 & 0.001 \\
\hline Past smoker (\%) & 30.9 & 34.0 & 40.2 & 35.6 & 30.0 & - & 43.0 & 46.4 & 45.9 & 48.7 & 43.6 & - \\
\hline Current smoker (\%) & 21.0 & 30.7 & 37.1 & 46.4 & 49.6 & - & 22.2 & 18.4 & 25.2 & 30.8 & 41.5 & - \\
\hline $\begin{array}{l}\text { Cumulative tobacco } \\
\text { consumption (pack years) }\end{array}$ & $16.6(24.7)$ & $18.9(21.9)$ & $24.5(25.9)$ & $29.8(26.8)$ & $33.1(29.3)$ & 0.001 & $17.7(23.7)$ & $14.6(20.2)$ & $16.7(20.7)$ & $19.8(21.9)$ & $29.6(26.3)$ & 0.001 \\
\hline \multicolumn{13}{|l|}{ Medical treatment } \\
\hline For hypertension (\%) & 7.6 & 9.6 & 6.2 & 7.2 & 7.9 & 0.39 & 14.8 & 13.1 & 13.1 & 12.8 & 14.1 & 0.66 \\
\hline For dyslipidemia (\%) & 0.7 & 1.2 & 1.0 & 1.4 & 1.7 & 0.71 & 9.8 & 11.5 & 13.1 & 11.3 & 11.4 & 0.17 \\
\hline For diabetes (\%) & 1.1 & 1.0 & 0.7 & 0.9 & 0 & 0.59 & 5.0 & 2.7 & 2.3 & 2.3 & 2.7 & 0.003 \\
\hline Waist circumference $(\mathrm{cm})$ & $91.0(9.4)$ & $91.0(8.6)$ & $91.1(9.7)$ & $92.3(9.2)$ & $90.8(10.3)$ & 0.42 & $94.5(10.9)$ & $95.1(10.0)$ & $94.7(9.2)$ & $96.1(9.2)$ & $98.7(10.1)$ & 0.001 \\
\hline Body mass index $\left(\mathrm{kg} / \mathrm{m}^{2}\right)$ & $26.2(3.4)$ & $26.1(3.2)$ & $26.1(3.5)$ & $26.6(3.1)$ & $26.1(3.8)$ & 0.36 & $26.5(3.8)$ & $26.6(3.5)$ & $26.4(3.1)$ & $26.8(3.3)$ & $27.4(3.6)$ & 0.001 \\
\hline $\begin{array}{l}\text { Systolic blood pressure } \\
(\mathrm{mm} \mathrm{Hg})\end{array}$ & $\begin{array}{l}132.0 \\
(19.3)\end{array}$ & $\begin{array}{l}132.8 \\
(20.9)\end{array}$ & $\begin{array}{l}134.7 \\
(19.8)\end{array}$ & $\begin{array}{l}138.3 \\
(20.4)\end{array}$ & $\begin{array}{l}139.0 \\
(22.8)\end{array}$ & 0.001 & $\begin{array}{l}131.1 \\
(18.4)\end{array}$ & $\begin{array}{l}132.0 \\
(17.7)\end{array}$ & $\begin{array}{l}132.2 \\
(18.1)\end{array}$ & $\begin{array}{l}134.7 \\
(18.1)\end{array}$ & $\begin{array}{l}138.8 \\
(18.9)\end{array}$ & 0.001 \\
\hline $\begin{array}{l}\text { Diastolic blood pressure } \\
(\mathrm{mm} \mathrm{Hg})\end{array}$ & $81.0(11.3)$ & $81.4(11.3)$ & $82.2(11.8)$ & $84.1(10.9)$ & $94.4(12.8)$ & 0.001 & $83.4(12.8)$ & $83.8(11.5)$ & $83.4(11.4)$ & $84.9(11.5)$ & $86.8(11.5)$ & 0.001 \\
\hline Triglyceride concentration (g/l) & $1.63(0.92)$ & $1.67(0.92)$ & $1.73(0.91)$ & $2.01(1.45)$ & $2.02(1.66)$ & 0.001 & $1.31(0.73)$ & $1.32(0.81)$ & $1.35(0.82)$ & $1.45(1.03)$ & $1.68(1.40)$ & 0.001 \\
\hline $\begin{array}{l}\text { High density lipoprotein } \\
\text { cholesterol concentration (g/l) }\end{array}$ & $0.43(0.11)$ & $0.46(0.11)$ & $0.49(0.14)$ & $0.49(0.13)$ & $0.52(0.16)$ & 0.001 & $0.45(0.11)$ & $0.48(0.12)$ & $0.50(0.12)$ & $0.51(0.13)$ & $0.53(0.14)$ & 0.001 \\
\hline $\begin{array}{l}\text { Total cholesterol } \\
\text { concentration }(\mathrm{g} / \mathrm{l})\end{array}$ & $2.23(0.38)$ & $2.28(0.39)$ & $2.32(0.39)$ & $2.30(0.40)$ & $2.30(0.41)$ & 0.001 & $2.07(0.36)$ & $2.16(0.35)$ & $2.21(0.36)$ & $2.23(0.37)$ & $2.29(0.42)$ & 0.001 \\
\hline $\begin{array}{l}\text { Apolipoprotein A-1 } \\
\text { concentration }(\mathrm{g} / \mathrm{l})\end{array}$ & $1.38(0.20)$ & $1.45(0.21)$ & $1.53(0.25)$ & $1.54(0.25)$ & $1.58(0.26)$ & 0.001 & $1.38(0.21)$ & $1.46(0.22)$ & $1.51(0.24)$ & $1.54(0.24)$ & $1.58(0.25)$ & 0.001 \\
\hline $\begin{array}{l}\text { Apolipoprotein B } \\
\text { concentration (g/l) }\end{array}$ & $1.34(0.31)$ & $1.36(0.33)$ & $1.37(0.33)$ & $1.39(0.37)$ & $1.36(0.37)$ & 0.34 & $1.18(0.26)$ & $1.22(0.28)$ & $1.24(0.30)$ & $1.26(0.33)$ & $1.32(0.38)$ & 0.001 \\
\hline
\end{tabular}

level was associated with non-drinking in France but with the heaviest drinking in Belfast $(\mathrm{P}=0.001$ for both).

Incidence of ischaemic heart disease

After 10 years' follow-up, 322 (3.3\%) incident hard coronary events $(127(5.3 \%) v 195(2.6 \%)$ in Belfast and the French centres, respectively) and 361 (3.7\%) incident angina events were identified $(120(5.0 \%) v 241$ (3.3\%), respectively). In France, the numbers of hard coronary events were similar in the three centres: 69 (2.8\%), 66 $(2.6 \%)$, and $60(2.5 \%)$ in Strasbourg, Toulouse, and Lille, respectively. A comparable picture was observed for angina events: 74 (3.1\%), 89 (3.6\%), and $78(3.2 \%)$ in Strasbourg, Toulouse, and Lille, respectively.

Annual incidence of hard coronary events per 1000 participants was 5.63 (95\% confidence interval 4.69 to 6.69) in Belfast and 2.78 (95\% CI 2.41 to 3.20) in the French centres. Annual incidence of angina was 5.46 (95\% CI 4.53 to 6.54$)$ and 3.49 (95\% CI 3.06 to 3.96$)$ per 1000 participants, respectively.

In all French centres combined, the proportion of individuals who experienced a hard coronary event differed significantly across categories of alcohol volume $(\mathrm{P}=0.02$; table 3$)$. This relation was not observed in Belfast. In both countries, the highest incidence of hard coronary events was noted in the non-drinking groups $(6.4 \%$ in Belfast and $4.6 \%$ in the French centres). Whatever the category of alcohol consumption, the proportions of individuals who experienced a hard coronary event or an angina event were always higher in Belfast than in the French centres.

\section{Alcohol consumption and ischaemic heart disease}

After multivariate adjustment for centre or country and classic cardiovascular risk factors (age, tobacco consumption, years of education, level of physical activity, systolic blood pressure, apolipoprotein A-1 and apolipoprotein B concentration, waist circumference, and treatment for hypertension, diabetes, and dyslipidaemia), alcohol consumption patterns remained associated with the occurrence of hard coronary events, regardless of country (Belfast $\mathrm{P}<0.02$; France $\mathrm{P}<0.02$; and in all centres $\mathrm{P}<0.001$; global Wald $\chi^{2}$ test; fig 1 ). Conversely, alcohol intake was not associated with incidence of angina pectoris.

The risk of hard coronary events in binge drinkers and in never drinkers was very similar and was about twofold higher than in regular alcohol drinkers. The 
Table 3 | Incident ischaemic heart disease events according to level of alcohol consumption in Belfast and the French centres

\begin{tabular}{|c|c|c|c|c|c|c|c|c|c|c|c|c|}
\hline & \multicolumn{6}{|c|}{ Belfast } & \multicolumn{6}{|c|}{ French centres } \\
\hline & $\begin{array}{c}\text { Non- } \\
\text { drinkers } \\
(n=949)\end{array}$ & $\begin{array}{c}1-24 \mathrm{~g} / \\
\text { day } \\
(n=576)\end{array}$ & $\begin{array}{c}25-49 \mathrm{~g} / \\
\text { day } \\
(n=418)\end{array}$ & $\begin{array}{c}50-74 \mathrm{~g} / \\
\text { day } \\
(n=222)\end{array}$ & $\begin{array}{c}\geq 75 \mathrm{~g} / \\
\text { day } \\
(n=240)\end{array}$ & $P$ value & $\begin{array}{c}\text { Non- } \\
\text { drinkers } \\
(n=694)\end{array}$ & $\begin{array}{c}1-24 \mathrm{~g} / \\
\text { day } \\
(n=221)\end{array}$ & $\begin{array}{c}25-49 \mathrm{~g} / \\
\text { day } \\
(n=1996)\end{array}$ & $\begin{array}{c}50-74 \mathrm{~g} / \\
\text { day } \\
(\mathrm{n}=1332)\end{array}$ & $\begin{array}{c}\geq 75 \mathrm{~g} / \\
\text { day } \\
(n=1134)\end{array}$ & $P$ value \\
\hline Hard coronary events (n (\%)) & $61(6.4)$ & $22(3.8)$ & $26(6.2)$ & $9(4.1)$ & $9(3.8)$ & 0.12 & $32(4.6)$ & $55(2.5)$ & $47(2.4)$ & $28(2.1)$ & $33(2.9)$ & 0.02 \\
\hline Angina events (n (\%)) & $43(4.5)$ & $28(4.9)$ & $24(5.7)$ & $14(6.3)$ & $11(4.6)$ & 0.77 & $24(3.5)$ & $70(3.2)$ & 77 (3.9) & $35(2.6)$ & $35(3.1)$ & 0.38 \\
\hline
\end{tabular}

hazard ratio for hard coronary events in binge drinkers compared with regular drinkers was 1.81 (95\% CI 1.05 to 3.11 ) in Belfast and 1.93 (95\% CI 0.46 to 7.40$)$ in the French centres. In all centres combined, the hazard ratio for developing hard coronary events compared with regular drinkers was 2.03 (95\% CI 1.41 to 2.94$)$ in never drinkers and 1.97 (95\% CI 1.21 to 3.22$)$ in binge drinkers. This difference between never drinkers and binge drinkers was not significant $\left(\mathrm{P}=0.91\right.$; Wald $\chi^{2}$ test). In the entire cohort, the hazard ratio for former drinkers in comparison with regular drinkers was 1.57 (95\% CI 1.11 to 2.21). There was no significant difference between the hazard ratios of former drinkers and never drinkers. Both in Belfast and in the French centres, the volume of alcohol intake and the frequency of alcohol consumption were not associated with the risk of developing hard coronary events in regular drinkers (fig 2 and fig 3).

We performed regression analyses with polynomial models (quadratic and cubic) using alcohol intake as a continuous variable to examine for possible non-linear relations between alcohol volume and the occurrence of hard coronary events. The parsimonious linear specification was adopted because the second and third order polynomial terms were not consistently significant, whatever the model. For an increase of $10 \mathrm{~g}$ in the amount of alcohol consumed a day, the risk of developing hard coronary events in regular drinkers was 1.04 (95\% CI 0.97 to $1.12 ; \mathrm{P}=0.31)$ in Belfast, $0.98(95 \% \mathrm{CI}$ 0.93 to $1.04 ; \mathrm{P}=0.59)$ in the French centres, and 1.01 $(95 \%$ CI 0.96 to $1.05 ; \mathrm{P}=0.73)$ in the whole cohort $(\mathrm{P}=0.11$ for interaction centre $\times$ alcohol volume $)$.

Wine drinking compared to not drinking wine was associated with a lower risk of hard coronary events in regular alcohol drinkers after multivariate adjustment (age, centre, tobacco consumption, years of education, level of physical activity, systolic blood pressure, apolipoprotein A-1, apolipoprotein B, waist circumference, treatment for hypertension, diabetes and dyslipidaemia), whereas no significant association was found for beer compared with no beer or other alcoholic beverages versus no other alcoholic beverages (table 4). Further adjustment for volume of alcohol consumed or for weekly frequency of alcohol consumption did not change the results significantly. Interactions between types of alcohol drinks (wine $v$ beer, wine $v$ other drinks, and beer $v$ other drinks) were not significant. Two by two comparisons showed significant differences in the risk of hard coronary events between wine and beer drinking and between wine and other types of alcohol when all centres were pooled.
Alcohol consumption and ischaemic heart disease in Belfast versus France

The risk of developing ischaemic heart disease in Belfast in comparison with the French centres for the whole cohort (drinkers and non-drinkers) is given in table 5 . Hazard ratios gradually decreased after successive adjustment for classic risk factors (age, centre, tobacco consumption, years of education, physical activity, systolic blood pressure, apolipoprotein A-1 and apolipoprotein B concentration, waist circumference, and treatment for hypertension, diabetes, and dyslipidaemia), drinking status, and wine drinking. The decreasing trend was more substantial for hard coronary events than for angina pectoris.

Among non-drinkers in the cohort, the hazard ratios for hard coronary events and angina pectoris in Belfast compared with in France were 1.36 (95\% CI 0.88 to
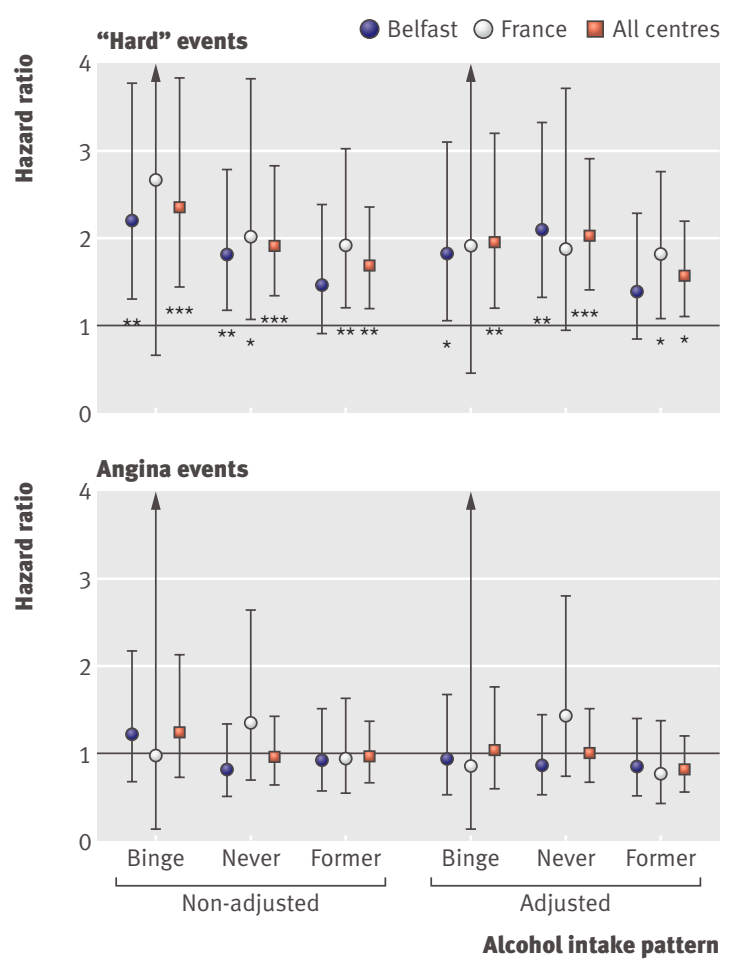

Fig 1 Hazard ratios for ischaemic heart disease in binge drinkers, never drinkers, and former drinkers in Belfast and in three centres in France, with regular drinkers as reference. Hazard ratios are adjusted for age, centre or country, tobacco consumption, years of education, level of physical activity, systolic blood pressure, apolipoprotein A-1 and apolipoprotein B concentration, waist circumference, and treatment for hypertension, diabetes, and dyslipidaemia. ${ }^{*} \mathrm{P}<0.05,{ }^{* \star \mathrm{P}}<0.01$, ${ }^{\star \star \star} \mathrm{P}<0.001$ 
Table 4 | Hazard ratios for hard coronary events in regular drinkers according to type of drink

\begin{tabular}{|c|c|c|c|c|c|c|c|c|c|}
\hline & \multicolumn{2}{|c|}{ Beer (yes $v$ no) } & \multicolumn{2}{|c|}{ Wine (yes $v$ no) } & \multicolumn{2}{|c|}{ Other drinks (yes $v$ no) } & \multicolumn{3}{|c|}{ Interactions } \\
\hline & $\begin{array}{l}\text { Hazard ratio } \\
(95 \% \mathrm{Cl})\end{array}$ & $P$ value & $\begin{array}{l}\text { Hazard ratio } \\
(95 \% \mathrm{Cl})\end{array}$ & $P$ value & $\begin{array}{l}\text { Hazard ratio } \\
(95 \% \mathrm{Cl})\end{array}$ & $P$ value & Wine $v$ beer & $\begin{array}{l}\text { Wine } v \text { other } \\
\text { drinks }\end{array}$ & $\begin{array}{l}\text { Beer } v \text { other } \\
\text { drinks }\end{array}$ \\
\hline \multicolumn{10}{|l|}{ Belfast } \\
\hline Non-adjusted & 2.09 (0.86 to 5.07$)$ & 0.11 & 0.39 (0.16 to 0.93$)$ & 0.04 & $1.30(0.71$ to 2.40$)$ & 0.39 & - & - & - \\
\hline Adjusted* & 1.75 (0.68 to 4.46$)$ & 0.25 & $0.51(0.20$ to 1.27$)$ & 0.51 & $1.28(0.68$ to 2.41$)$ & 0.45 & - & - & - \\
\hline Interaction† & - & - & - & - & - & - & 0.39 & 0.99 & 0.99 \\
\hline $\begin{array}{l}\text { Two by two } \\
\text { comparison } \ddagger \S\end{array}$ & - & - & - & - & - & - & $4.1(0.05)$ & $2.7(0.10)$ & $0.4(0.54)$ \\
\hline \multicolumn{10}{|l|}{ France } \\
\hline Non-adjusted & 0.87 (0.64 to 1.19$)$ & 0.40 & 0.59 (0.37 to 0.95$)$ & 0.03 & $1.08(0.76$ to 1.56$)$ & 0.65 & - & - & - \\
\hline Adjusted* & $0.86(0.61$ to 1.19$)$ & 0.36 & 0.65 (0.40 to 1.07$)$ & 0.09 & 0.99 (0.69 to 1.42$)$ & 0.95 & - & - & - \\
\hline Interaction† & - & - & - & - & - & - & 0.24 & 0.19 & 0.94 \\
\hline $\begin{array}{l}\text { Two by two } \\
\text { comparison } \ddagger \S\end{array}$ & - & - & - & - & - & - & $0.9(0.34)$ & $1.8(0.18)$ & $0.3(0.58)$ \\
\hline \multicolumn{10}{|l|}{ All centres } \\
\hline Non-adjusted & 0.99 (0.75 to 1.33$)$ & 0.98 & $0.52(0.36$ to 0.76$)$ & 0.001 & 1.09 (0.80 to 1.49$)$ & 0.57 & - & - & - \\
\hline Adjusted* & $0.93(0.69$ to 1.27$)$ & 0.67 & $0.57(0.38$ to 0.85$)$ & 0.006 & $1.03(0.75$ to 1.41$)$ & 0.87 & - & - & - \\
\hline Interaction $†$ & - & - & - & - & - & - & 0.90 & 0.42 & 0.89 \\
\hline $\begin{array}{l}\text { Two by two } \\
\text { comparison } \ddagger \S\end{array}$ & - & - & - & - & - & - & $4.4(0.04)$ & $5.3(0.03)$ & $0.2(0.67)$ \\
\hline
\end{tabular}

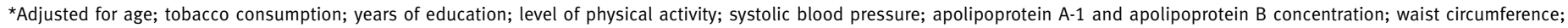
treatment for hypertension, diabetes, and dyslipidaemia; total alcohol; and centre. Binge drinkers were excluded from the analyses.

$\dagger P$ value for interaction, tested in adjusted models

fWald $X^{2}$ test ( $P$ value), tested in adjusted models.

$\S$ Comparisons between wine and beer, wine and other drinks, and beer and other drinks.

$2.08 ; \mathrm{P}=0.16)$ and $1.25(95 \% \mathrm{CI} 0.76$ to $2.06 ; \mathrm{P}=0.37)$ in crude analyses. After multivariate adjustment for classic risk factors, these hazard ratios were 1.27 (95\% CI 0.77 to $2.09 ; \mathrm{P}=0.35)$ and $1.26(95 \% \mathrm{CI} 0.69$ to 2.30 ; $\mathrm{P}=0.44$ ), respectively.

After multivariate adjustment for classic risk factors and alcohol consumption, the hazard ratio for hard coronary events among regular drinkers in Belfast compared with the French centres was notably reduced, from $1.61(95 \% \mathrm{CI} 1.16$ to 2.22$)$ to 1.02 (95\% CI 0.66 to 1.57$)$.

\section{DISCUSSION}

Main findings

In this prospective cohort study, we investigated the effect of alcohol consumption on the incidence of ischaemic heart disease in two countries, Northern Ireland and France. We found that alcohol consumption patterns differed radically in the two countries: in Belfast most men's alcohol intake was concentrated on one day of the weekend (Saturday), whereas in the three French centres studied alcohol consumption was spread more evenly throughout the entire week. However, the volumes of alcohol consumed by drinkers over an entire week were similar in Belfast and in the French centres. ${ }^{3031}$

The prevalence of binge drinking, which doubled the risk of ischaemic heart disease compared with regular drinking, was almost 20 times higher in Belfast than in the French centres. Never drinkers, who were seven times more numerous in Belfast, had a risk of ischaemic heart disease similar to that of binge drinkers. However, our study's very low statistical power to detect subgroup differences does not permit the conclusion that binge drinking has an equivalent effect on the risk of ischaemic heart disease to nondrinking. In the same way, consumption of wine seems to be associated with lower risk of ischaemic heart disease whatever the country, but the small numbers again do not allow for firm conclusions.

The differences between countries in the incidence of coronary heart disease reported in the WHO MONICA register study (mid-1990s) ${ }^{24}$ were con-

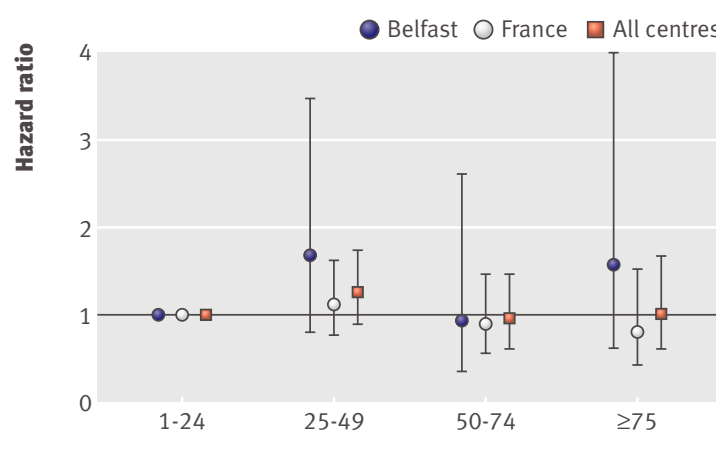

Volume of alcohol consumption (g/day)

Fig 2| Hazard ratios for hard coronary events according to volume of alcohol consumption in regular drinkers compared with alcohol consumption of 1-24 g/day. Hazard ratios are adjusted for age, centre or country, tobacco consumption, years of education, level of physical activity, systolic blood pressure, apolipoprotein A-1 and apolipoprotein B concentration, waist circumference, and treatment for hypertension, diabetes, and dyslipidaemia 
Table $5 \mid$ Hazard ratios for ischaemic heart disease in Belfast in relation to the French centres

\begin{tabular}{|c|c|c|c|c|}
\hline & \multicolumn{2}{|c|}{ Hard coronary events } & \multicolumn{2}{|c|}{ Angina pectoris events } \\
\hline & $\begin{array}{l}\text { Hazard ratio } \\
(95 \% \mathrm{Cl})\end{array}$ & $P$ value & $\begin{array}{l}\text { Hazard ratio } \\
(95 \% \mathrm{Cl})\end{array}$ & $P$ value \\
\hline Non-adjusted & 2.03 (1.62 to 2.53$)$ & 0.001 & 1.57 (1.26 to 1.96$)$ & 0.001 \\
\hline Adjusted for classic risk factors* & 1.76 (1.37 to 2.67$)$ & 0.001 & 1.32 (1.04 to 1.69$)$ & 0.03 \\
\hline $\begin{array}{l}\text { Adjusted for classic risk factors and } \\
\text { drinking status } \dagger\end{array}$ & 1.35 (1.02 to 1.80$)$ & 0.04 & 1.35 (1.04 to 1.77 ) & 0.03 \\
\hline $\begin{array}{l}\text { Adjusted for classic risk factors, } \\
\text { drinking status, and wine drinking }\end{array}$ & 1.09 (0.79 to 1.50$)$ & 0.59 & $1.28(0.93$ to 1.75$)$ & 0.13 \\
\hline
\end{tabular}

*Adjusted for age, centre, tobacco consumption, years of education, level of physical activity, systolic blood pressure, apolipoprotein A-1 and apolipoprotein B concentration, waist circumference, and treatment for hypertension, diabetes, and dyslipidaemia.

tDrinking status was regular drinker, binge drinker, never drinker, or former drinker.

firmed in PRIME. The crude incidence of hard coronary events in the entire PRIME cohort was twice as high in Belfast as in the French centres. Different drinking habits could play a substantial role in the disparity between Belfast and the French centres. A residual differential risk for hard coronary events between Belfast and the French centres persisted in non-drinkers after multivariate adjustment.

\section{Strengths and limitations of study}

PRIME was based on a common protocol that was strictly applied in both Northern Ireland and France in a large sample of middle aged men who were broadly representative of their respective background populations. In addition, a very high follow-up was achieved over 10 years, with only approximately 5\% attrition from the cohort. Patterns of alcohol consumption (volume, binge drinking, and types of drink) at inclusion were similar among men who dropped out to in men who were still under our surveillance. Uniform validation of coronary heart disease outcomes was based on previously established WHO MONICA criteria. Furthermore, data relating to all suspected events were examined by the same ad hoc medical committee. A code was assigned to each event according to a standardised protocol.

The prospective analyses presented were based on men free of ischaemic heart disease at inclusion. A potential weakness of the study is the absence of a detailed history of alcohol consumption behaviour. It has been claimed that "abstainer misclassification error" can at least partially account for an observed lower incidence of coronary heart disease in regular drinkers compared with non-drinkers if a proportion of the non-drinkers has given up on account of ill health (sick quitters) ${ }^{32}$ This is an unlikely explanation for the associations observed in PRIME because only participants free of disease at baseline were included in the prospective analysis and the pattern of risk factors in table 2 does not suggest that the non-drinkers as a whole were any less healthy than the drinkers.

Alcohol patterns were assessed once at inclusion and were not estimated during the course of the follow-up. Changes in alcohol habits during the follow-up period could have had an effect on the relation of alcohol consumption with ischaemic heart disease. Demographic factors influence alcohol consumption behaviour ${ }^{3334}$ and our study has investigated a very homogeneous population of men aged 50-59 years, so we cannot generalise our results to women and to other age groups. The use of "typical weekly consumption" as a reference may underestimate the prevalence of infrequent binge drinking, but probably more so in the French than in the Northern Irish population, where binge drinking on weekends seems to be a well established pattern.

\section{Comparison with other studies}

In this study we confirmed the well known association between alcohol consumption and incidence of hard coronary events. ${ }^{5-8}$ Conversely, no association was observed for all types of incident angina pectoris or when subtypes of angina, both stable and unstable, were tested separately (data not shown). These findings suggest that the pathophysiological mechanism of the effect of drinking on ischaemic heart disease and its clinical expression are more likely to be related to thrombosis than to atherosclerosis. ${ }^{35}$

Our results for regular drinkers are at variance with the few other published studies that have comparable data, ${ }^{3637}$ where the amount of alcohol consumed and drinking frequency were not associated with the risk of incident hard coronary events in regular drinkers. However, when our entire cohort (including binge drinkers and non-drinkers) was considered, as the number of drinking days increased, the risk of incident hard coronary events decreased, confirming the inverse associations previously reported in both men and women. ${ }^{19}$

Binge drinking is common in northern Europe and the United States compared with Mediterranean countries. ${ }^{38}$ In the Onset Study ${ }^{20}$ mortality after acute myocardial infarction was twofold higher in binge

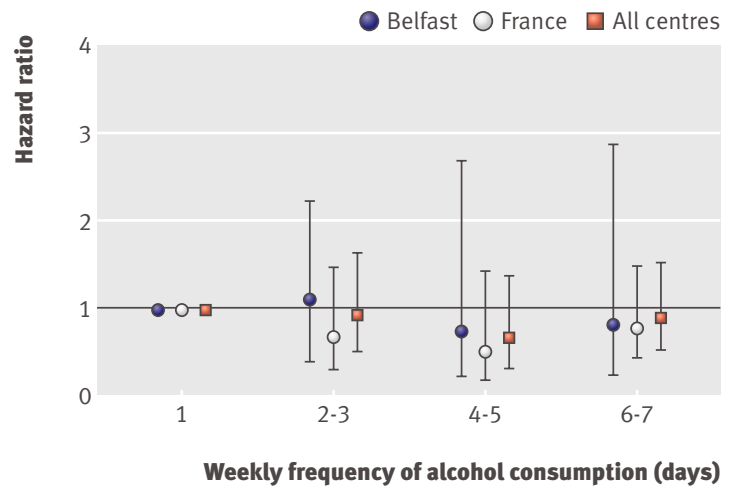

Fig 3 | Hazard ratios for hard coronary events according to weekly frequency of alcohol consumption in regular drinkers compared with alcohol consumption of 1 day/week. Hazard ratios are adjusted for age, centre or country, tobacco consumption, years of education, level of physical activity, systolic blood pressure, apolipoprotein A-1 and apolipoprotein B concentration, waist circumference, and treatment for hypertension, diabetes, and dyslipidaemia 


\section{WHAT IS ALREADY KNOWN ON THIS TOPIC}

Alcohol consumption is associated with ischaemic heart disease

Recent evidence suggests that certain drinking habits, such as binge drinking, might increase the risk of ischaemic heart disease

Drinking patterns may contribute to the disparity in the incidence of ischaemic heart disease observed between Belfast and the French centres

\section{WHAT THIS STUDY ADDS}

Most (90.6\%) middle aged men in France and nearly two thirds (60.5\%) in Belfast reported drinking alcohol at least once a week

Heavy or binge drinking is associated with a higher risk of ischaemic heart disease than is regular drinking

A greater proportion of men in Belfast binge drink than in France, which may explain some of the higher risk of ischaemic heart disease in Belfast

drinkers than in drinkers who did not binge, both in heavy and in light drinkers, suggesting that a risk exists for episodic alcohol intake, even when the amount consumed is moderate. In PRIME, when two or three days of alcohol intake greater than $50 \mathrm{~g}$ were considered, the risk of developing incident hard coronary events tended to be similar to the risk associated with a single day's heavy drinking. Episodic consumption seems at least as crucial as the volume of alcohol consumed in determining the positive association between binge drinking and the incidence of hard coronary events. The association of binge drinking with coronary heart disease mortality (cardiovascular deaths or sudden death) has been noted more often in previous studies ${ }^{20-2339}$ than the association with cardiovascular morbidity. ${ }^{18}$

The role of the type of alcoholic beverage in the relation between drinking pattern and ischaemic heart disease is another important factor that has been debated. A favourable effect of wine on the incidence of ischaemic heart disease or on mortality rates is often reported in populations where wine is the predominant alcoholic beverage consumed, ${ }^{40}$ whereas inverse associations between beer or spirits and ischaemic heart disease are observed in populations characterised by a high intake of these alcoholic drinks. ${ }^{6}$ In our study, wine drinking was associated with a lower risk of ischaemic heart disease, both in Belfast and the French centres. Thus we suggest that wine consumption in itself is of greater importance than the volume of wine consumed and that wine associated behaviour is at least as significant as wine consumption. A study conducted in France showed that people who drink moderate quantities of alcohol and wine drinkers have healthier behaviours and a reduced level and frequency of cardiovascular risk factors than abstainers and people who drink other beverages. ${ }^{41}$ Wine drinking in Belfast tended to be associated with people of higher socioeconomic status in whom health expectations are better (data not shown).The biological effects of alcohol depend on how much and how often alcohol is consumed. ${ }^{42}$ This association has been attributed to the relation between alcohol and high density lipoprotein cholesterol, fibrinogen, and haemoglobin $\mathrm{A}_{1 \mathrm{C}},{ }^{19}$ and temporary changes in the fibrinolytic system. ${ }^{43}$ The higher blood pressure levels observed in Belfast on Mondays and Tuesdays are associated with the binge drinking pattern in they city. ${ }^{44}$ Moreover, a randomised crossover trial has shown in participants unaccustomed to alcohol consumption that acute ingestion of a large and tolerable dose of alcohol induces changes in the normal circadian periodicity of the haemostatic system. ${ }^{45}$

\section{Conclusions and policy implications}

Our findings have important public health implications. The regions we studied are within countries for which alcohol consumption is the highest recorded worldwide and is of a similar order of magnitude (11$14 \mathrm{l}$ of pure ethanol per capita in adults per annum). ${ }^{4647}$ The high proportion of heavy or binge drinking among alcohol drinkers in these two populations carries a serious risk of ischaemic heart disease.

Data from WHO shows a trend towards harmonisation across countries in consumption levels, beverage preferences, and heavy or binge drinking, especially in Europe. ${ }^{47}$ The prevalence of binge drinking, which was formerly a marginal drinking behaviour in the majority of Mediterranean countries, has tended to increase, particularly in the younger generation. Education has a pivotal role in any prevention campaign to reduce harmful drinking habits. The alcohol industry takes every opportunity to imbue alcohol consumption with a positive image, emphasising its beneficial effects on risk of ischaemic heart disease, but people also need to be informed about the health consequences of heavy drinking.

Patterns of alcohol consumption, with the exception of the average amount of alcohol consumed a week by drinkers, varied considerably between Belfast and the French centres. In both countries, the same behaviours were associated with a similar risk of ischaemic heart disease. Binge and irregular heavy drinking doubled the risk of developing myocardial infarction in comparison to regular and moderate drinking. Consuming a high quantity of alcohol on each drinking occasion, which characterises binge drinking, was particularly prevalent in Belfast and could contribute to the higher risk of ischaemic heart disease observed there. From our data alone, however, it is difficult to conclude whether the pattern of alcohol intake has a major role in the incidence of ischaemic heart disease independent of other behaviours, such as diet.

We thank the following organisations that allowed the recruitment of participants for the Prospective Epidemiological Study of Myocardial Infarction (PRIME): the health screening centres organised by the Social Security of Lille (Institut Pasteur), Strasbourg, Toulouse, and Tourcoing; the occupational medicine services of Haute-Garonne; the Urban Community of Strasbourg; the Association Inter-entreprises des Services Médicaux du Travail de Lille et environs; the Comité pour le Développement de la Médecine du Travail; the Mutuelle Générale des Postes, Télégraphes et Téléphones du Bas-Rhin; the Laboratoire d'Analyses de l'Institut de Chimie Biologique de la Faculté de Médecine de Strasbourg; the Department of Health ( $\mathrm{NI})$; and the Northern Ireland Chest Heart and Stroke Association. We also thank the Alliance 
Partnership Programme for its financial support and the following members of the event validation committees: L Guize; C Morrison; M-T Guillanneuf; and M Giroud.

Contributors: The authors were responsible for all the aspects of the study design; the collection, analysis, and the interpretation of the data; the writing of the report; and the decision to submit the article for publication. J-BR performed analyses and wrote the manuscript. PD, AE, and FK are the guarantors of data analyses and contributed to the redrafting of the manuscript.

Funding: PRIME was supported by grants from the Institut National de la Santé et de la Recherche Médicale (INSERM) and the Merck, Sharp \& Dohme-Chibret Laboratory.

Competing interests: All authors have completed the Unified Competing Interest form at www.icmje.org/coi_disclosure.pdf (available on request from the corresponding author) and declare: no support from any organisation for the submitted work; no financial relationships with any organisations that might have an interest in the submitted work in the previous 3 years; no other relationships or activities that could appear to have influenced the submitted work.

Data sharing: Technical appendix and statistical code are available from Jean-Bernard Ruidavets (jean-bernard.ruidavets@cict.fr). Data are available from the PRIME study group (coordinating centre: Pierre Ducimetière, CESP, Villejuif, F-94807, France. pierre.ducimetiere@inserm.fr) subject to an end user authorisation agreement

1 World Health Organization (WHO) Geneva Switzerland. WHO global infobase for cardiovascular diseases. https://apps.who.int/ infobase.

2 Rehm J, Mathers C, Popova S, Thavorncharoensap M, Teerawattananon Y, Patra J. Global burden of disease and injury and economic cost attributable to alcohol use and alcohol-use disorders. Lancet 2009;373:2223-33.

3 Anderson P. Binge drinking and Europe. Deutsche Hauptstelle für Suchtfragen (DHS),

2008. http://www.ias.org.uk/resources/papers/europe/phproject/ bingedrinking-report.pdf.

4 Centers for Disease Control and Prevention. Alcohol-related disease impact (ARDI) system. US Department of Health and Human Services, 2009. https://apps.nccd.cdc.gov/ardi/Homepage.aspx.

5 Marmot MG, Shipley MJ. Do socioeconomic differences in mortality persist after retirement? 25 year follow up of civil servants from the first Whitehall study. $B M$ J 1996;313:1177-80.

6 Maclure M. Demonstration of deductive meta-analysis: ethanol intake and risk of myocardial infarction. Epidemiol Rev 1993;15:328-51.

7 Rimm EB, Klatsky A, Grobbee D, Stampfer MJ. Review of moderate alcohol consumption and reduced risk of coronary heart disease: is the effect due to beer, wine, or spirits. BMJ 1996;312:731-6.

8 Rehm JT, Bondy SJ, Sempos CT, Vuong CV. Alcohol consumption and coronary heart disease morbidity and mortality. Am J Epidemiol 1997; 146:495-501.

9 O'Keefe JH, Bybee KA, Lavie CJ. Alcohol and cardiovascular health: the razor-sharp double-edged sword. J Am Coll Cardiol 2007;50:1009-14.

10 Gronbaek M. Alcohol and cardiovascular disease-more than on paradox to consider. Type of alcoholic beverage and cardiovascular disease-does it matter? J Cardiovasc Risk 2003;10:5-10.

11 Klatsky AL, Friedman GD, Armstrong MA, Kipp H. Wine, liquor, beer, and mortality. Am J Epidemiol 2003:158:585-95.

12 Mukamal KJ, Conigrave KM, Mittleman MA, Camargo CA Jr, Stampfer MJ, Willett WC, et al. Roles of drinking pattern and type of alcohol consumed in coronary heart disease in men. $\mathrm{N}$ Engl J Med 2003;348:109-18.

13 Di Castelnuovo A, Rotondo S, lacoviello L, Donati MB, De Gaetano G. Meta-analysis of wine and beer consumption in relation to vascular risk. Circulation 2002;105:2836-44.

14 Rimm EB. Alcohol consumption and coronary heart disease: good habits may be more important than just good wine. Am I Epidemiol 1996;143:1094-8.

15 Wannamethee SG, Shaper AG. Type of alcoholic drink and risk of major coronary heart disease events and all-cause mortality. $\mathrm{Am}$ Public Health 1999;89:685-90.

16 Fuchs FD, Chambless LE, Folsom AR, Eigenbrodt ML, Duncan BB, Gilbert A, et al. Association between alcoholic beverage consumption and incidence of coronary heart disease in whites and blacks: the Atherosclerosis Risk in Communities Study. Am J Epidemiol 2004;160:466-74.

17 Poikolainen K, Vartiainen E. Wine and good subjective health. Am J Epidemiol 1999;150:47-50.

18 Murray RP, Connett JE, Tyas SL, Bond R, Ekuma O, Silversides CK, et al. Alcohol volume, drinking pattern, and cardiovascular disease morbidity and mortality: is there a U-shaped function? Am J Epidemiol 2002;155:242-8.

19 Mukamal KJ, Jensen MK, Grønbaek M, Stampfer MJ, Manson JE, Pischon T, et al. Drinking frequency, mediating biomarkers, and risk of myocardial infarction in women and men. Circulation 2005;112:1406-13.

20 Mukamal KJ, Maclure M, Muller JE, Mittleman MA. Binge drinking and mortality after acute myocardial infarction. Circulation 2005;112:3839-45.

21 Kauhanen J, Kaplan GA, Goldberg DE, Salonen JT. Beer binging and mortality: results from the Kuopio ischaemic heart disease risk factor study, a prospective population based study. $B M$ 1997;315:846-51.

22 Britton A, McKee M. The relation between alcohol and cardiovascular disease in Eastern Europe: explaining the paradox. J Epidemiol Community Health 2000;54:328-32.

23 Malyutina S, Bobak M, Kurilovitch S, Gafarov V, Simonova G, Nikitin Y, et al. Relation between heavy and binge drinking and allcause and cardiovascular mortality in Novosibirsk, Russia: a prospective cohort study. Lancet 2002;360:1448-54.

24 Tunstall-Pedoe H, Kuulasmaa K, Mahonen M, Tolonen H, Ruokokoski E, Amouyel P. Contribution of trends in survival and coronary-event rates to changes in coronary heart disease mortality: 10-year results from 37 WHO MONICA project populations. Monitoring trends and determinants in cardiovascular disease. Lancet 1999;353:1547-57.

25 Yarnell JW. The PRIME study: classical risk factors do not explain the several fold differences in risk of coronary heart disease between France and Northern Ireland. Prospective Epidemiological Study of Myocardial Infarction. O/M 1998;91:667-76.

26 Rose GA. The diagnosis of ischaemic heart pain and intermittent claudication in field surveys. Bull World Health Organ 1962;27:645-58.

27 Rose GA, Blackburn H, Gillum RF, Prineas RJ. Cardiovascular Survey Methods. 2nd ed. World Health Organization, 1982.

28 Ducimetière P, Ruidavets IB, Montaye M, Haas B, Yarnell J. Five-yea incidence of angina pectoris and other forms of coronary heart disease in healthy men aged 50-59 in France and Northern Ireland: the Prospective Epidemiological Study of Myocardial Infarction (PRIME) Study. Int J Epidemiol 2001;30:1057-62.

29 Lin DY, Wei L, Ying Z. Checking the Cox model with cumulative sums of martingale-based residuals. Biometrika 1993;80:557-72.

30 Evans AE, Ruidavets JB, McCrum EE, Cambou JP, McClean R, Douste-Blazy P, et al. Autres pays, autres coeurs? Dietary patterns, risk factors and ischaemic heart disease in Belfast and Toulouse. OJM 1995;88:469-77.

31 Marques-Vidal P, Arveiler D, Evans A, Montaye M, Bingham A, Ruidavets JB, et al. Patterns of alcohol consumption in middle-aged men from France and Northern Ireland: the PRIME study. Eur J Clin Nutr 2000;54:321-8

32 Fillmore KM, Stockwell T, Chikritzhs T, Bostrom A, Kerr W. Moderate alcohol use and reduced mortality risk: systematic error in prospective studies and new hypotheses. Ann Epidemiol 2007;17 (suppl 5): 16-23S.

33 Kerr WC, Greenfield TK, Bond J, Ye Y, Rehm J. Age-period-cohort modelling of alcohol volume and heavy drinking days in the US National Alcohol Surveys: divergence in younger and older adult trends. Addiction 2009;104:27-37.

34 Karlamangla A, Zhou K, Reuben D, Greendale G, Moore A. Longitudinal trajectories of heavy drinking in adults in the United States of America. Addiction 2006;101:91-9.

35 Clark LT. Atherogenesis and thrombosis: mechanisms, pathogenesis, and therapeutic implications. Am Heart 1992;123:1106-9.

36 Camargo CA Jr, Stampfer MJ, Glynn RJ, Grodstein F, Gaziano JM, Manson JE, et al. Moderate alcohol consumption and risk for angina pectoris or myocardial infarction in U.S. male physicians. Ann Intern Med 1997;126:372-5.

37 Kitamura A, Iso H, Sankai T, Naito Y, Sato S, Kiyama M, et al. Alcohol intake and premature coronary heart disease in urban Japanese men. Am J Epidemiol 1998;147:59-65.

38 Kuntsche E, Rehm J, Gmel G. Characteristics of binge drinkers in Europe. Soc Sci Med 2004;59:113-27.

39 Rehm J, Greenfield TK, Rogers JD. Average volume of alcohol consumption, patterns of drinking, and all-cause mortality: results from the US National Alcohol Survey. Am J Epidemiol 2001;153:64-71.

40 Farchi G, Fidanza F, Mariotti S, Menotti A. Alcohol and mortality in the Italian rural cohorts of the Seven Countries Study. Int J Epidemiol 1992;21:74-81.

41 Ruidavets IB, Bataille V, Dallongeville I, Simon C, Bingham A, Amouyel P, et al. Alcohol intake and diet in France, the prominent role of lifestyle. Eur Heart / 2004;25:1153-62. 
42 McElduff P, Dobson AJ. How much alcohol and how often? Population based case-control study of alcohol consumption and risk of a major coronary event. BMJ 1997;314:1159-64.

43 Hendriks HF, Veenstra J, Velthuis-te Wierik EJ, Schaafsma G, Kluft C. Effect of moderate dose of alcohol with evening meal on fibrinolytic factors. BMJ 1994;308:1003-6.

44 Marques-Vidal P, Arveiler D, Evans A, Amouyel P, Ferrières J, Ducimetière $P$. Different alcohol drinking and blood pressure relationships in France and Northern Ireland: the PRIME Study. Hypertension 2001;38:1361-6.
45 Numminen H, Syrjala M, Benthin G, Kaste M, Hillbom M. The effect of acute ingestion of a large dose of alcohol on the hemostatic system and its circadian variation. Stroke 2000;31:1269-73.

46 Rehm J, Rehn N, Room R, Monteiro M, Gmel G, Jernigan D, et al. The global distribution of average volume of alcohol consumption and patterns of drinking. Eur Addict Res 2003;9:147-56.

47 World health Organization (WHO). Global Status Report on Alcohol 2004. Country Profiles. http://www.who.int/substance_abuse/ publications/statusreportalcoholeuro/en/index.html.

Accepted: 09 September 2010 